\title{
Assessment of dental arch stability after orthodontic treatment and oral rehabilitation in complete unilateral cleft lip and palate and non-clefts patients using 3D stereophotogrammetry
}

Maria Giulia Rezende Pucciarelli ${ }^{1} \mathbb{D}$, Guilherme Hideki de Lima Toyoshima ${ }^{1} \mathbb{B}$, Thais Marchini Oliveira² (D, Heitor Marques Honório ${ }^{3}$ (D) Chiarella Sforza ${ }^{4}$ (D) and Simone Soares ${ }^{5^{*}}$ (D)

\begin{abstract}
Background: Although arch stability has been studied in patients without a cleft, evidence for patients with a cleft is sparse. Therefore, we compared the dimensions and stability of dental arches in cleft lip and palate patients and those without a cleft.

Methods: Forty participants, 20 with a complete unilateral cleft lip and palate and 20 non-cleft patients aged from 18 to 30 years, with anterior and/or posterior crossbite and receiving orthodontic treatment were evaluated retrospectively. Eighty gypsum casts were digitized using a laser model scanner casts for both groups made immediately after the orthodontic treatment was completed (T1). Also, for the Cleft Lip and Palate group, casts were obtained and digitized 1 year after implant-supported rehabilitation (T2) and for the Non-Cleft Lip and Palate group, 1 year after the conclusion of the orthodontic treatment (T2). The formula: $\Delta=\mathrm{T} 2-\mathrm{T} 1$ evaluated the stability of dental arches for inter-canine distances (C-C'), inter-molar distances (M-M'), arch length (I-M), palate surface and volume. The dimensions of the dental arches were measured digitally. The independent $t$ test was used for statistical analysis $(a=0.05)$.
\end{abstract}

Results: A statistical difference was found in the stability of the groups for inter-canine (cleft area) measurement. At the times T1 and T2, a statistically significant difference was found in the arch length, surface and volume.

Conclusions: This study concluded that in the Cleft Lip and Palate group, the maxillary dimensions were not stabilized after 1 year of orthodontic and prosthodontic treatment (mainly for the inter-canine linear measurement) and that the transverse arch dimensions were smaller compared with those of non-cleft patients.

Keywords: Cleft lip, Cleft palate, Dental arch, Three-dimensional imaging, Rehabilitation, Orthodontic appliances

\footnotetext{
*Correspondence: sisoares@usp.br

${ }^{5}$ Department of Prosthodontics and Periodontology, Bauru School of

Dentistry and Hospital of Rehabilitation of Craniofacial Anomalies, University

of São Paulo, Alameda Dr. Octávio Pinheiro Brisolla, 9-75, Bauru, São Paulo

17012-901, Brazil

Full list of author information is available at the end of the article
}

(C) The Author(s). 2020 Open Access This article is licensed under a Creative Commons Attribution 4.0 International License, which permits use, sharing, adaptation, distribution and reproduction in any medium or format, as long as you give appropriate credit to the original author(s) and the source, provide a link to the Creative Commons licence, and indicate if changes were made. The images or other third party material in this article are included in the article's Creative Commons licence, unless indicated otherwise in a credit line to the material. If material is not included in the article's Creative Commons licence and your intended use is not permitted by statutory regulation or exceeds the permitted use, you will need to obtain permission directly from the copyright holder. To view a copy of this licence, visit http://creativecommons.org/licenses/by/4.0/ The Creative Commons Public Domain Dedication waiver (http://creativecommons.org/publicdomain/zero/1.0/) applies to the data made available in this article, unless otherwise stated in a credit line to the data. 


\section{Background}

Craniofacial anomalies comprise a large group of congenital defects, of which the most prevalent nonsyndromic malformation is cleft lip and palate, affecting 1 in 500-700 births, and thus considered a relevant public health problem according to the World Health Organization [1]. Patients with cleft lip and palate (CLP) are identified and typically treated with primary plastic surgeries (cheiloplasty and palatoplasty) usually performed before 12 months of age [2]. Despite rehabilitating esthetics and function, these primary surgeries result in a deleterious effect on maxillary growth [3, 4], with shorter antero-posterior dimension of the alveolar arch in unilateral CLP patients [5]. Rehabilitation is not completed with the anatomic repair of the cleft [2], but requires an interdisciplinary team $[2,6]$ to achieve anatomic and functional rehabilitation up to skeletal maturity $[7,8]$.

The treatment of choice to rehabilitate the cleft area is orthodontics [2]. However, the rehabilitative treatment is challenging because the anatomic and functional alterations are directly linked to the malformation type and the age at the beginning the treatment. Obtaining ideal intermaxillary relationships and occlusion, as well as post-treatment stability, requires proper alignment of the teeth in both dental arches, with adequate overjet and overbite $[9,10]$. Therefore, many patients require different types of dental prosthesis to rehabilitate the edentulous cleft area, typically the lateral incisor area [11]. Rehabilitating the cleft area with osseointegrated dental implants rather than a fixed dental prosthesis is based on an implant survival rate of $90 \%$ at the cleft area [12], similar to that found in patients without a cleft [13].

A systematic clinical documentation protocol comprising all the growth period from birth to adulthood of individuals with oral clefts enables appropriate and prospective planning through tailoring the management required at the many treatment phases [14] and the longitudinal evaluation of the treatment progress [15]. Through study casts, changes in the craniofacial growth can be diagnosed by an analysis of the transversal, anterior-posterior $[16,17]$ and vertical dental relations [16]. Three-dimensional analysis of dental arches improves data collection [15, 18-22].

Studies comparing the maxillary dimensions after rehabilitative treatment of adult individuals with and without oral clefts are lacking [23]. This information may help to better understand the relevant factors involving the complex rehabilitation of individuals with CLP and to determine parameters for protocols and future research.

This study aimed to compare the post-treatment stability of the linear measurements of adult individuals with a cleft at two phases of the interdisciplinary treatment with those of adults without clefts (18 to 30 years). The null hypothesis was that the post-treatment stability of the maxillary measurements of individuals with oral clefts would be similar to that of individuals without a cleft.

\section{Methods}

This retrospective study followed the Declaration of Helsinki on medical protocol and was approved by the Institutional Review Board regarding ethical aspects under protocol $\mathrm{n}^{\circ}$. 50808215.2.0000.5441 and in accordance with the STROBE guidelines.

A sample size calculation determined that to detect a minimum difference in maxillary width measurement of $0.8 \mathrm{~mm}$, with a standard deviation of $0.7 \mathrm{~mm}$, at a significance level of $5 \%$ and a power of $80 \%$, it was necessary to have a minimum of 15 participants per group, based on a pilot study and also from a previous study [24].

Gypsum casts of individuals with and without CLP selected respectively from files of the Hospital for Rehabilitation of Craniofacial Anomalies and Bauru School of Dentistry were digitized using a laser model scanner. The inclusion criteria for both groups were as follows: individuals with or without clefts aged between 18 and 30 years regularly enrolled in each institution with anterior and/or posterior crossbite, who had neither undergone orthognathic surgery nor premolar extraction, who did not wear full denture prosthesis and who had the adequately stored study casts at the study phases. Patients with associated syndromes or malformations or incomplete documentation were excluded.

Forty patients were selected from the 115 individuals evaluated and were divided in two groups: cleft lip and palate (CLP) group $(n=20)$ with complete unilateral cleft lip and palate who had received multidisciplinary treatment at the Hospital for Rehabilitation of Craniofacial Anomalies from birth, with primary surgeries, until the end of treatment when adult, with an implant placed in the cleft area; and the non-cleft group (NCLP), $(n=$ 20). A hundred and fifteen patients were assessed in the study, of which 75 (15 CLP and 60 NCLP) did not meet the eligibility criteria because the casts were not suitable for evaluation.

Both groups started and received similar orthodontic treatment lasting approximately 4 years. The long-term analysis was immediately after conclusion of the orthodontic treatment and then 1 year after the complete rehabilitation and orthodontic treatment. The evaluation was done at two times, immediately after removal of the orthodontic appliance and 1 year later, after prosthetic treatment in CLP patients and 1 year later in NCLP patients. 
Patients in the CLP group received primary surgery at 3 (cheiloplasty) and 12 (palatoplasty) months of age, respectively. Prior to the secondary alveolar bone graft (mean age 12 years), rapid maxillary expansion was performed, and definitively rehabilitated with prostheses supported by implants in the cleft area after bone growth had ceased. The mean age of the patients was $25.25 \pm 3.2$ (CLP group).

Rapid maxillary expansion (RME) was performed in both groups with Haas expanders attached to the canines and deciduous second molars and a lingual bar extended to the permanent first molars. The activation protocol was the same for all patients: one full swing per day ( $2 / 4$ in the morning and $2 / 4$ in the evening) for 7 days. After the active expansion, the device was maintained as retention for 6 months. The present study evaluated the patients immediately after the orthodontic appliance was removed and 1 year later. The stability of the dental arches was the main goal in this groups, if they were maintained or they are not stable, especially in the CLP group rehabilitated with an implant-supported prosthesis.

Eighty gypsum casts were digitized (3Shape R700TM Scanner, Copenhagen, Denmark), and the files were analyzed through the VAM elaboration software (Canfield Scientific, Inc., New Jersey, USA). The evaluation was conducted through 3D images of maxillary arch casts obtained at the following phases for the CLP group - T1: immediately after orthodontic treatment; T2: 1 year after prosthetic rehabilitation and for the NCLP group - T1: immediately after orthodontic treatment; T2: 1 year after orthodontic treatment.

To evaluate the stability of dental arches, the change between $\mathrm{T} 1$ and $\mathrm{T} 2$ was obtained through the following formula: $\Delta=\mathrm{T} 2-\mathrm{T} 1$ for each of the measures: intercanine distances $\left({\left.\mathrm{C}-\mathrm{C}^{\prime}\right)}^{\prime}\right)[18,25-27]$, inter-molar distances (M-M'), arch length (I-M) [25, 27, 28], palatal surface and volume $[5,24]$ (Table 1).

All measurements were made point-to-point by the software that started the acquisition of the image according to Cartesian planes. The anatomic reference points (Fig. 1, Table 1) were used in the maxillary arch to obtain the linear measurements $\left(\mathrm{C}-\mathrm{C}^{\prime}, \mathrm{M}-\mathrm{M}^{\prime}\right.$ and I$\mathrm{M})$. Limit points for surface and volume were established, although the posterior closure of the palate was done by the system to avoid operator error (Fig. 2).

\section{Error of method}

The measures were evaluated twice by the same examiner in $50 \%$ of the digitized models to analyze the error of the method 20 days after the first measurement. The random errors were calculated according to the Dahlberg' [29] formula $\left(\mathrm{Se}^{2}=\sum \mathrm{d}^{2} / 2 \mathrm{n}\right)$, where $\mathrm{Se}^{2}$ is the error variance and $d$ is the difference between two determinations of the same variable. The systematic errors were evaluated with the dependent $t$ test. No random and systematic errors were found between the measurements obtained on the two different occasions $(p \geq 0.05)$.

\section{Statistical analysis}

The measurements were compared through $t$ tests in all cases to evaluate the two groups (CLP and NCLP). The statistical analyses were performed with Sigmaplot version 12.5 (Systat Software Inc., San Jose, CA, USA) ( $\alpha=0.05$ for all tests).

\section{Results}

The CLP group was composed of 13 women and 7 men; mean age: $25.2 \pm 3.2$ and the NCLP group of 11 women and 9 men; mean age $22.4 \pm 4$.6. Immediately after the orthodontic treatment (T1), both groups demonstrated similar measurements, except for the arch length (I-M), palatal surface and volume (Table 2).

The individuals with a cleft showed a narrower arch length and smaller three-dimensional measurements (palatal surface and volume) than those without clefts. The same arch shape was maintained after rehabilitation (T2) (Table 3) when compared with Table 2, and the maxillary linear measurements $\mathrm{C}^{-\mathrm{C}^{\prime}}, \mathrm{M}-\mathrm{M}^{\prime}$ and $\mathrm{I}-\mathrm{M}$ decreased in the CLP group.

Table 1 The measurements of the maxillary dimensions $(\mathrm{mm})$, palate surface $\left(\mathrm{mm}^{2}\right)$ and volume $\left(\mathrm{mm}^{3}\right)$ evaluated

\begin{tabular}{|c|c|c|}
\hline $\begin{array}{l}\text { Linear measurements } \\
(\mathrm{mm})\end{array}$ & Abbreviations & Definition \\
\hline Inter-canine & $C-C^{\prime}$ & distance between the cusp tips of the canines. \\
\hline Intermolar & $M-M^{\prime}$ & distance between the tips of the mesial-buccal cusps of the first molars. \\
\hline Arch length & $I-M$ & $\begin{array}{l}\text { perpendicular line of the distance between the contact point and the maxillary central incisors up to the } \\
\text { intermolar line. }\end{array}$ \\
\hline Palate surface & - & $\begin{array}{l}\text { Limits standardized: the upper limit was determined by inter-incisor papilla, the lateral limit was surrounded all } \\
\text { marginal gingival limits of permanent teeth, and the posterior limit was the midpoint of the distal second } \\
\text { molar. }\end{array}$ \\
\hline Volume & - & $\begin{array}{l}\text { Limits standardized: the upper limit was determined by inter-incisor papilla, the lateral limit was surrounded all } \\
\text { marginal gingival limits of permanent teeth, and the posterior limit was the midpoint of the distal second } \\
\text { molar. }\end{array}$ \\
\hline
\end{tabular}




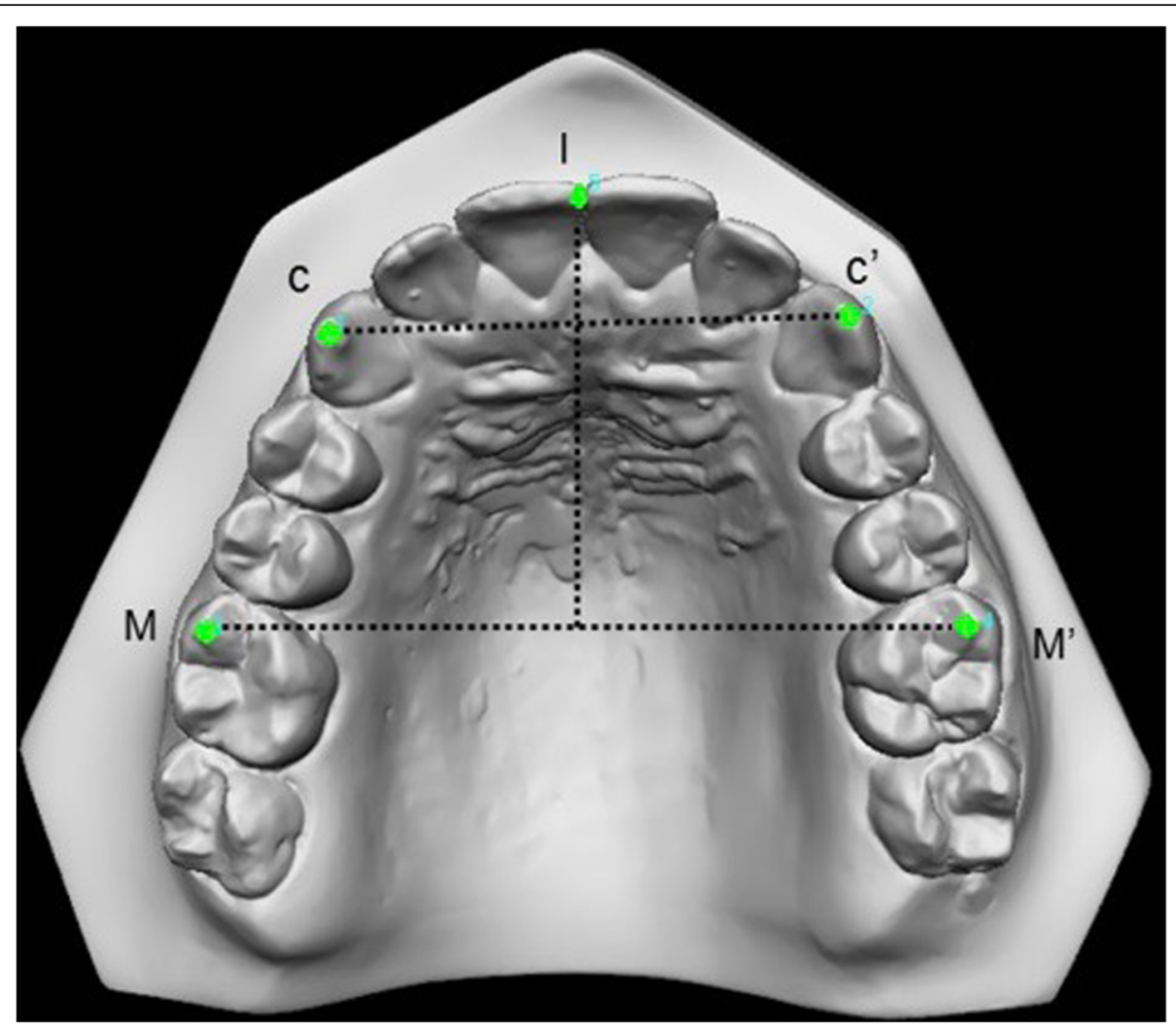

Fig. 1 Landmarks points in the maxillary arch for linear measurements (C-C', M-M' and I-M)

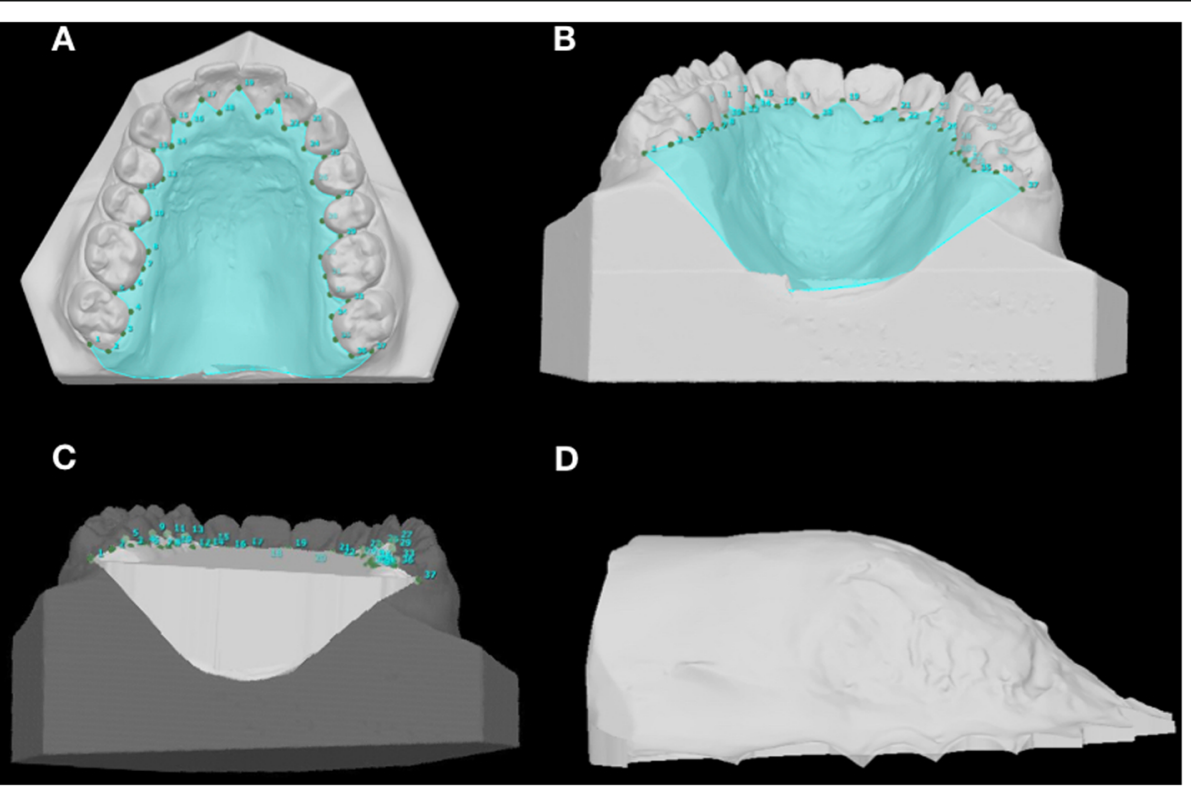

Fig. 2 Limits points for palate surface and volume. a Delimitate of palatal surface - Limits standardized: the upper limit was determined by interincisor papilla, the lateral limit was surrounded all gingival limits of permanent teeth, and the posterior limit was the midpoint of the distal second molar. b Delimitate of palate volume. c The volume selected. $\mathbf{d}$ Palate volume 
Table 2 Maxillary dimensions $(\mathrm{mm})$, palate surface $\left(\mathrm{mm}^{2}\right)$ and volume $\left(\mathrm{mm}^{3}\right)$ immediately after orthodontic treatment (T1)

\begin{tabular}{|c|c|c|c|c|}
\hline \multirow{2}{*}{$\begin{array}{l}\text { Variables } \\
\text { T1 }\end{array}$} & \multirow{2}{*}{$\begin{array}{l}\text { CLP } \\
\text { Mean } \pm S D\end{array}$} & \multicolumn{3}{|l|}{ NCLP } \\
\hline & & Mean $\pm S D$ & $95 \% \mathrm{Cl}$ & $p(\leq 0,05)$ \\
\hline $\mathrm{C}-\mathrm{C}^{\prime}$ & $34.82 \pm 5.18$ & $34.62 \pm 2.58$ & $-2.32-1.69$ & 0.91 \\
\hline M-M' & $51.54 \pm 3.61$ & $52.08 \pm 2.71$ & $2.58-1.50$ & 0.81 \\
\hline I-M & $26.81 \pm 3.81$ & $29.34 \pm 2.16$ & $-4.51-0.54$ & $0.01 *$ \\
\hline Surface & $19.55 \pm 2.80$ & $22.44 \pm 3.43$ & $-4.89-0.87$ & $0.006^{*}$ \\
\hline Volume & $7424.30 \pm 2463.02$ & $12,123.90 \pm 4043.92$ & $-6842.96-2556.23$ & $0.001 *$ \\
\hline
\end{tabular}

*Statistically significant at $p \leq 0,05$ t-test

CLP cleft lip and palate; NCLP non-cleft lip and palate; $C-C^{\prime}$, inter-canine distance; $M-M^{\prime}$ intermolar distance and $I-M$ arch length

The evaluation of stability $(\Delta)$ between the study phases (T2-T1) showed statistically significant differences between groups for the inter-canine measurement (C-C') (Table 4). The CLP group exhibited a proportional reduction in the transversal measurement, but the intermolar (M-M') and arch length measurement (IM) showed no statistically significant difference between the groups. A proportional variation in the linear measurements without statistically significant differences was observed for the NCLP group. Negative (-) values indicated a reduction in the maxillary dimensions.

\section{Discussion}

The study compared maxillary dimensional alterations in adult individuals with CLP from the Hospital for Rehabilitation of Craniofacial Anomalies at two treatment phases (after orthodontic treatment and after implantsupported prosthesis delivery) with those without CLP but receiving orthodontic treatment. The methodology, which was based on the relevant literature and used a digitized cast and a 3D analysis, resulted in a significant change in the data collected [15, 18-22].

Individuals with oral clefts underwent a long interdisciplinary treatment $[2,6,8,30,31]$ until skeletal maturity $[7,8]$ to rehabilitate the anatomic and functional deficiencies. The treatment protocol in the Hospital for Rehabilitation of Craniofacial Anomalies consisted of corrective primary surgeries during childhood, usually performed before 12 months of age [2], pediatric follow- up until adolescence, orthodontic evaluation and determination of the growth pattern, usually due to surgical interventions at childhood. These individuals with oral clefts had a Class III skeletal pattern caused by the maxillary sagittal deficiency, and maxillary expansion treatment is often necessary before secondary alveolar bone grafting [2, 24]. Ayub et al. (2016) compared the dentoalveolar effects of RME in individuals with and without clefts and found similar maxillary expansion results for both groups [24]. Thus, the comparison between adult individuals with and without CLP after orthodontic treatment (T1) was justified.

Individuals with CLP commonly have agenesis of the maxillary lateral incisor. The orthodontic treatment in individuals with CLP is complex and many factors should be carefully evaluated. Nevertheless, orthodontic treatment is the first choice for rehabilitating the edentulous space of the lateral incisor [2]. However, other options for the rehabilitation of the cleft area may be necessary, including different types of prosthesis [11,32].

Studies on adult individuals with CLP and long-term studies on the stability of rehabilitation/prosthetic treatment comparing individuals with and without oral clefts [23] are lacking. The digitized casts obtained during the treatment phases can provide more information on the treatment stability of individuals with oral clefts.

3D digital images have advantages, including rotation and manipulation similar to those of gypsum casts [31, $33,34]$, accurate measurements, improved handling and

Table 3 Maxillary dimensions $(\mathrm{mm})$, palate surface $\left(\mathrm{mm}^{2}\right)$, volume $\left(\mathrm{mm}^{3}\right)$, 1 year later after rehabilitation/orthodontic treatment (T2)

\begin{tabular}{|c|c|c|c|c|}
\hline \multirow{2}{*}{$\begin{array}{l}\text { Variables } \\
\text { T2 }\end{array}$} & \multirow{2}{*}{$\begin{array}{l}\text { CLP-R } \\
\text { Mean } \pm S D\end{array}$} & \multicolumn{3}{|l|}{ NCLP-OT } \\
\hline & & Mean \pm SD & $95 \% \mathrm{Cl}$ & $p(\leq 0,05)$ \\
\hline $\mathrm{C}-\mathrm{C}^{\prime}$ & $32.28 \pm 5.52$ & $34.60 \pm 2.65$ & $-2.87-0.98$ & 0.40 \\
\hline$M-M^{\prime}$ & $50.62 \pm 3.24$ & $51.71 \pm 2.92$ & $-3.06-0.88$ & 0.13 \\
\hline I-M & $26.26 \pm 3.14$ & $29.02 \pm 2.37$ & $-4.53-0.97$ & $0.003^{*}$ \\
\hline Surface & $18.63 \pm 3.55$ & $22.16 \pm 2.62$ & $-5.53-1.53$ & $0.001 *$ \\
\hline Volume & $7297.50 \pm 5351.00$ & $11,725.0 \pm 4802.50$ & $-6233.64-2424.05$ & $0.001 *$ \\
\hline
\end{tabular}

*Statistically significant at $p \leq 0,05$; t-test

CLP cleft lip and palate; NCLP non-cleft lip and palate; $C-C^{\prime}$, inter-canine distance; $M-M^{\prime}$ intermolar distance and $I-M$ arch length; R, rehabilitation; OT, orthodontic treatment 
Table 4 Stability $(\Delta=T 2-T 1)$ of the maxillary dimensions $(\mathrm{mm})$, palate surface $\left(\mathrm{mm}^{2}\right)$ and volume $\left(\mathrm{mm}^{3}\right)$ between groups

\begin{tabular}{lllll}
\hline Variables & CLP & NCLP & & \\
& Mean \pm SD & Mean \pm SD & $95 \% \mathrm{Cl}$ & $\mathbf{0}(\leq 0,05)$ \\
\hline $\boldsymbol{\Delta C}$ & $-0.42 \pm 1.25$ & $0.10 \pm 0.02$ & $-1.55-0.30$ & 0.35 \\
$\Delta \mathbf{M}$ & $-0.47 \pm 1.01$ & $-0.40 \pm 1.02$ & $-1.37-0.27$ & 0.69 \\
$\Delta \mathbf{M}$ & $-0.35 \pm 1.19$ & $-0.25- \pm 0.75$ & $-1.07-0.63$ & 0.36 \\
Surface & $-0.92 \pm 1.89$ & $-0.27 \pm 2.52$ & $-2.07-0.78$ & 0.55 \\
Volume & $420.85 \pm 1723.18$ & $50.10 \pm 2151.25$ & $-876.94-1618.44$ & \\
\hline
\end{tabular}

*Statistically significant at $p \leq 0,05$ t-test

$C L P$ cleft lip and palate; NCLP non-cleft lip and palate; $\triangle C$ inter-canine distance; $\triangle M$ intermolar distance and $\triangle I M$, arch length

storage, planning and execution of the various stages of rehabilitation treatment $[21,22]$. These advantages were important in this study, since two treatment phases were considered (T1 and T2). Moreover, the study of these phases enabled the long-term evaluation of the stability of the maxillary dimensions during treatment.

Landmarks have been used to perform the linear measurements for evaluating the maxillary dimensions and changes over time in individuals with a cleft lip and palate from an early age to assess the growth and maxillary bone development [18, 25, 26, 28, 33-36]. In this present study, we used strategic landmarks for the evaluation of maxillary dimensions at the permanent dentition: intercanine distance $\left(\mathrm{C}-\mathrm{C}^{\prime}\right)$ [3], intermolar distance (M-M') [3], arch length (I-M) [24], palatal surface and volume [5] (Table 1).

The cleft typically affects the alveolar ridge, causing tooth agenesis (generally the lateral incisor) [2] and requiring prosthetic treatment. However, this study only evaluated patients who received implants in the cleft area, enabling a comparison between groups. Both groups were selected to enable the analysis of the intercanine, intermolar and arch length measurements. This would not have been possible if the sample had included individuals with clefts in whom the canine was mesialized to close the lateral incisor space. Because of this, our sample was a convenience sample. When a treatment is concluded in a CLP patient, regardless of dental treatment, the parameters or gold standard are based on NCLP patients, and therefore these two groups were compared.

The intergroup stability comparison revealed a statistically significant difference in the inter-canine measurement $\left(\mathrm{C}-\mathrm{C}^{\prime}\right)$, and the dimensional alteration demonstrated a reduction of $-0.42 \mathrm{~mm}$ during the study period. Notably, the non-stabilized area is near the cleft after 1 year of rehabilitation (Table 4), while the other measurements analyzed demonstrated stability. As expected, the cleft area is the most vulnerable to orthodontic relapse.

At T1 (immediately after the orthodontic treatment), individuals with CLP had a lower arch length (I-M) than non-cleft individuals, while inter-canine $\left(\mathrm{C}-\mathrm{C}^{\prime}\right)$ and intermolar measurements $\left(\mathrm{M}-\mathrm{M}^{\prime}\right)$ were not statistically different between groups (Table 2). This result is consistent with that of Ayub et al. [24] and Athanasiou et al. [35], who reported that the arch length of individuals with CLP is smaller than that of individuals without CLP from the deciduous to the permanent dentition [24, 35]. The analysis of the linear measurements' stability (T2T1) revealed that non-cleft individuals exhibited a proportional stability in all measurements, without statistically significant differences (Table 4). In contrast, individuals with CLP showed statistically significant difference in the inter-canine $\left(C-C^{\prime}\right)$ measurement (Table 4), with a reduction of $-0.42 \mathrm{~mm}$. Similarly, Li and Lin (2007) assessed the post-treatment stability of individuals with a cleft and concluded that relapse occurred to some extent after orthodontic treatment and arch width decreased after retention [3].

The present study also found a statistically significant difference in the palatal surface (T1 $p=0.006 / \mathrm{T} 2 p=$ $0.001)$ and volume (T1/T2 $p=0.001)$ between the groups at both times studied. Rusková et al. (2014) reported similar results when comparing palatal volume in unilateral cleft and non-cleft patients and concluded the average of volume in the CLP group was shallower, narrower, shorter and more asymmetrical [5]. These findings were supported by other studies which determined that palate width as a whole was reduced compared with controls [36, 37] CLP individuals typically have smaller palate surfaces than non-cleft individuals [38], which suggests that there is an intrinsic tissue deficiency in the palate/maxilla before palatoplasty (Lo et al., 2003) and that after the primary surgeries, the dental arch narrows [39].

These dimensional alterations in the maxillary arch of individuals with a cleft are a challenge for the rehabilitation treatment, which requires periodic follow-ups after orthodontic treatment and implant installation to check the prosthesis and the occlusion. Occlusal adjustments are often necessary in individuals with CLP, a fact that can be explained by the dental changes occurring over time, as identified by this study. It is important to 
emphasize that the relapse of the upper arch in CLP patients it is not enough to cause posterior crossbite after 1 year, and the alterations can be seen in an anterior arch with regular occlusal adjustments. Whether the implant-supported prothesis influences the arch stabilization is unclear. The results of the present study suggest that rehabilitation with implants did not stabilize the dimensions of the maxillary arches, but more studies are necessary with different types of prothesis to determine the outcome.

Limitations of the study included not evaluating orthodontic relapse, since only the maxillary dental arches were assessed. An evaluation of relapse should include bone development and occlusion, which was outside the scope of this investigation. An additional limitation was the convenience sample, because the eligibility criteria were so specific.

This study was conducted on individuals treated at one rehabilitation center, and thus, the results should be extrapolated with caution. Intercenter studies are necessary to illuminate the growth and stability of the rehabilitative treatment in individuals with a cleft lip and palate.

\section{Conclusion}

In the CLP group, the maxillary dimensions were not stabilized after 1 year with orthodontic and implantsupported prostheses as compared with non-cleft patients, and the palate surface and volume were smaller compared with non-cleft patients. Oral rehabilitation specialists should be careful when treating this kind of patient.

\section{Abbreviations}

CLP: Cleft lip and palate; NCLP: Non-cleft lip and palate; RME: Rapid maxillary expansion; T1: Immediately after orthodontic treatment; T2: 1 year after prosthetic treatment; C-C': Inter-canine distance; M-M': Inter-molar distance; IM: Arch length

\section{Acknowledgements}

The authors thank the patients from Hospital for Rehabilitation of Craniofacial Anomalies/University of São Paulo and thank authors: Jorge Tomasio Caballero, Victor Fabrizio Cabrera Pazmiño and Márcio de Menezes.

\section{Authors' contributions}

MGRP, GHLT contributed to the collection of data; HMH contributed to data analysis interpretation. TMO and SS contributed to coordinating the participants and drafted the manuscript. TMO, SS, and CS contributed to conception design and interpretation of data. All authors gave final approval and agree to be accountable for all aspects of the work.

\section{Funding}

The study was supported by FAPESP (Fundação de Apoio à Pesquisa do Estado de São Paulo), grant: 2016/14942-6. FAPESP supported the acquisition of stereophotogrammetry VECTRA H1.

\section{Availability of data and materials}

The datasets used and/or analyzed during the current study are not publicly available but are available from the corresponding author on reasonable request.

\section{Ethics approval and consent to participate}

The study followed the Declaration of Helsinki on medical protocol and was approved by the Institutional Review Board from Hospital for Rehabilitation of Craniofacial Anomalies/University of São Paulo, proceeding number 1.522.353 - Brazil Platform, regarding ethical aspects under protocol $\mathrm{n}^{\circ}$. 50808215.2.0000.5441. No administrative permissions and/or licenses were acquired to access the data used in our research.

\section{Consent for publication}

Not applicable.

\section{Competing interests}

The authors declare that they have no competing interests.

\section{Author details}

${ }^{1}$ Bauru School of Dentistry/Hospital for Rehabilitation of Craniofacial Anomalies, University of São Paulo, Bauru, São Paulo, Brazil. 'Department of Pediatric Dentistry, Orthodontics and Public Health, Bauru School of Dentistry and Hospital of Rehabilitation of Craniofacial Anomalies, University of São Paulo, Bauru, São Paulo, Brazil. ${ }^{3}$ Department of Pediatric Dentistry, Orthodontics and Public Health, Bauru School of Dentistry, University of São Paulo, Bauru, São Paulo, Brazil. ${ }^{4}$ Faculty of Medicine and Surgery, Department of Biomedical Sciences for Health, Functional Anatomy Research Center (FARC), Università degli Studi di Milano, Milan, Italy. ${ }^{5}$ Department of Prosthodontics and Periodontology, Bauru School of Dentistry and Hospital of Rehabilitation of Craniofacial Anomalies, University of São Paulo, Alameda Dr. Octávio Pinheiro Brisolla, 9-75, Bauru, São Paulo 17012-901, Brazil.

Received: 21 February 2020 Accepted: 19 May 2020

Published online: 27 May 2020

\section{References}

1. de Freitas JA S, das Neves LT, de Almeida ALPF, et al. Rehabilitative treatment of cleft lip and palate: experience of the Hospital for Rehabilitation of craniofacial anomalies/USP (HRAC/USP)--part 1: overall aspects. J Appl Oral Sci. 2012;20(1):9-15. https://doi.org/10.1590/s167877572012000100003

2. de Freitas JA S, Garib DG, Oliveira M, et al. Rehabilitative treatment of cleft lip and palate: experience of the Hospital for Rehabilitation of craniofacial anomalies - USP (HRAC-USP) - part 2: pediatric dentistry and orthodontics. J Appl Oral Sci. 2012;20(2):268-81. https://doi.org/10.1590/s167877572012000200024

3. Li W, Lin J. Dental arch width stability after quadhelix and edgewise treatment in complete unilateral cleft lip and palate. Angle Orthod. 2007; 77(6):1067-72. https://doi.org/10.2319/070506-272.1.

4. Bichara LM, Araújo RC, Flores-Mir C, Normando D. Impact of primary palatoplasty on the maxillomandibular sagittal relationship in patients with unilateral cleft lip and palate: a systematic review and meta-analysis. Int J Oral Maxillofac Surg. 2015;44(1):50-6. https://doi.org/10.1016/j.ijom.2014.08. 004.

5. Rusková H, Bejdová Š, Peterka M, Krajíček V, Velemínská J. 3-D shape analysis of palatal surface in patients with unilateral complete cleft lip and palate. J Craniomaxillofacial Surg. 2014;42(5):e140-7. https://doi.org/10.1016/j.jcms. 2013.07.011

6. Wang G, Yang Y, Wang K, et al. Current status of cleft lip and palate management in China. J Craniofac Surg. 2009;20(Suppl 2):1637-9. https:// doi.org/10.1097/SCS.0b013e3181b1c1ae.

7. Aljohar A, Ravichandran K, Subhani S. Pattern of cleft lip and palate in hospital-based population in Saudi Arabia: retrospective study. Cleft Palate Craniofac J. 2008;45(6):592-6. https://doi.org/10.1597/06-246.1.

8. Rocha R, Ritter DE, Locks A, De Paula LK, Santana RM. Ideal treatment protocol for cleft lip and palate patient from mixed to permanent dentition. Am J Orthod Dentofac Orthop. 2012;141(4 Suppl):S140-8. https://doi.org/10. 1016/j.ajodo.2011.03.024.

9. Akcam MO, Toygar TU, Özer L, Özdemir B. Evaluation of 3-dimensional tooth crown size in cleft lip and palate patients. Am J Orthod Dentofac Orthop. 2008;134(1):85-92. https://doi.org/10.1016/j.ajodo.2006.05.048.

10. Antonarakis GS, Tsiouli K, Christou P. Mesiodistal tooth size in nonsyndromic unilateral cleft lip and palate patients: a meta-analysis. Clin Oral Investig. 2013;17(2):365-77. https://doi.org/10.1007/s00784-012-0819-9. 
11. de Souza FREITAS JA, das NEVES LT, de ALMEIDA ALPF, et al. Rehabilitative treatment of cleft lip and palate: experience of the Hospital for Rehabilitation of craniofacial anomalies/USP (HRAC/USP) - part 4: Oral rehabilitation. J Appl Oral Sci. 2013;21(3):284-92. https://doi.org/10.1590/ 1679-775720130127.

12. Kearns G, Perrott DH, Sharma A, Kaban LB, Vargervik K. Placement of endosseous implants in grafted alveolar clefts. Cleft Palate Craniofac J. 1997;34:520-5. https://doi.org/10.1597/1545-1569_1997_034_0520_ poeiig_2.3.co_2.

13. Adell R, Lekholm U, Rockler B, Brånemark PI. A 15-year study of osseointegrated implants in the treatment of the edentulous jaw. Int J Oral Surg. 1981;10(6):387-416. https://doi.org/10.1016/s0300-9785(81)80077-4.

14. Wutzl A, Sinko K, Shengelia N, et al. Examination of dental casts in newborns with bilateral complete cleft lip and palate. Int J Oral Maxillofac Surg. 2009;38(10):1025-9. https://doi.org/10.1016/j.jom.2009.04.023.

15. Mello BZF, Fernandes VM, Carrara CFC, Machado MAAM, Garib DG, Oliveira TM. Evaluation of the intercanine distance in newborns with cleft lip and palate using 3D digital casts. J Appl Oral Sci. 2013;21(5):437-42. https://doi. org/10.1590/1679-775720130091.

16. Lilja J, Mars M, Elander A, et al. Analysis of dental arch relationships in Swedish unilateral cleft lip and palate subjects: 20-year longitudinal consecutive series treated with delayed hard palate closure. Cleft Palate Craniofac J. 2006;43(5):606-11. https://doi.org/10.1597/05-069.

17. Sinko K, Caacbay E, Jagsch R, Turhani D, Baumann A, Mars M. The GOSLON yardstick in patients with unilateral cleft lip and palate: review of a Vienna sample. Cleft Palate Craniofac J. 2008;45(1):87-92. https://doi.org/10.1597/06-118.1.

18. Sforza C, De Menezes M, Bresciani $E$, et al. Evaluation of a $3 D$ stereophotogrammetric technique to measure the stone casts of patients with unilateral cleft lip and palate. Cleft Palate Craniofac J. 2012;49(4):47783. https://doi.org/10.1597/10-207.

19. Sforza C, de Menezes M, Ferrario VF. Soft- and hard-tissue facial anthropometry in three dimensions: What's new. J Anthropol Sci. 2013;91: 159-84. https://doi.org/10.4436/jass.91007.

20. Huanca Ghislanzoni LT, Lineberger M, Cevidanes LH, Mapelli A, Sforza C, McNamara JA. Evaluation of tip and torque on virtual study models: a validation study. Prog Orthod. 2013;14(1):19. https://doi.org/10.1186/21961042-14-19.

21. Kuijpers MAR, Chiu Y-T, Nada RM, Carels CEL, Fudalej PS. Three-dimensional imaging methods for quantitative analysis of facial soft tissues and skeletal morphology in patients with Orofacial clefts: a systematic review. PLoS One. 2014;9(4):e93442. https://doi.org/10.1371/journal.pone.0093442.

22. De Menezes M, Ceron-Zapata AM, Lopez-Palacio AM, Mapelli A, Pisoni L, Sforza C. Evaluation of a three-dimensional Stereophotogrammetric method to identify and measure the palatal surface area in children with unilateral cleft lip and palate. Cleft Palate Craniofac J. 2016;53(1):16-21. https://doi. org/10.1597/14-076.

23. Caballero JT, Pucciarelli MGR, Pazmiño VFC, Curvêllo VP, Menezes M, Sforza C, Soares S. 3D comparison of dental arch stability in patients with and without cleft lip and palate after orthodontic/rehabilitative treatment. J App Oral Sci. 2019;27:e20180434. https://doi.org/10.1590/1678-7757-2018-0434.

24. Ayub PV, Janson G, Gribel BF, Lara TS, Garib DG. Analysis of the maxillary dental arch after rapid maxillary expansion in patients with unilateral complete cleft lip and palate. Am J Orthod Dentofac Orthop. 2016;149(5): 705-15. https://doi.org/10.1016/j.ajodo.2015.11.022.

25. Reiser E, Skoog V, Andlin-Sobocki A. Early dimensional changes in maxillary cleft size and arch dimensions of children with cleft lip and palate and cleft palate. Cleft Palate Craniofac J. 2013;50(4):481-90. https://doi.org/10.1597/ 11-003.

26. Falzoni $\mathrm{M}$, Jorge $\mathrm{P}$, Laskos $\mathrm{K}$, et al. Three-dimensional dental arch evaluation of children with unilateral complete cleft lip and palate. Dent Oral Craniofac Res. 2016;2(2):238-41.

27. Carrara CC, Ambrosio EP, Mello BF, et al. Three-dimensional evaluation of surgical techniques in neonates with orofacial cleft. Ann Maxillofac Surg. 2016;6(2):246. https://doi.org/10.4103/2231-0746.200350.

28. Hoffmannova E, Bejdová Š, Borský J, Dupej J, Cagáňová V, Velemínská J. Palatal growth in complete unilateral cleft lip and palate patients following neonatal cheiloplasty: classic and geometric morphometric assessment. Int J Pediatr Otorhinolaryngol. 2016;90:71-6. https://doi.org/10.1016/j.ijporl.2016. 08.028.

29. Dahlberg G. Statistical methods for medical and biological students. London: George Allen and Urwin; 1940.
30. de Freitas JA S, Trindade-Suedam IK, Garib DG, et al. Rehabilitative treatment of cleft lip and palate: experience of the Hospital for Rehabilitation of craniofacial anomalies/USP (HRAC/USP) - part 5: institutional outcomes assessment and the role of the Laboratory of Physiology. J Appl Oral Sci. 2013;21(4):383-90. https://doi.org/10.1590/1678775720130290.

31. Vargervik K, Oberoi S, Hoffman WY. Team care for the patient with cleft: UCSF protocols and outcomes. J Craniofac Surg. 2009;20(Suppl 2):1668-71. https://doi.org/10.1097/SCS.0b013e3181b2d6e3.

32. Pucciarelli MGR, Lopes ACO, Lopes JFS, Soares S. Implant placement for patients with cleft lip and palate: a clinical report and guidelines for treatment. J Prosthet Dent. 2019 Jan;121(1):9-12. https://doi.org/10.1016/j. prosdent.2018.01.020.

33. Leifert MF, Leifert MM, Efstratiadis SS, Cangialosi TJ. Comparison of space analysis evaluations with digital models and plaster dental casts. Am J Orthod Dentofacial Orthop. 2009;136(1):16.e1-4; discussion 16. https://doi. org/10.1016/j.ajodo.2008.11.019.

34. Bootvong K, Liu Z, McGrath C, et al. Virtual model analysis as an alternative approach to plaster model analysis: reliability and validity. Eur J Orthod. 2010;32(5):589-95. https://doi.org/10.1093/ejo/cjp159.

35. Athanasiou AE, Mazaheri M, Zarrinnia K. Dental arch dimensions in patients with unilateral cleft lip and palate. Cleft Palate J. 1988;25(2):139-45.

36. Kilpeläinen PVJ, Laine-Alava MT. Palatal asymmetry in cleft palate subjects. Cleft Palate Craniofac J. 1996;33(6):483-8. https://doi.org/10.1597/15451569_1996_033_0483_paicps_2.3.co_2.

37. Šmahel Z, Trefný P, Formánek P, Müllerová Ž, Peterka M. Three-dimensional morphology of the palate in subjects with unilateral complete cleft lip and palate at the stage of permanent dentition. Cleft Palate Craniofac J. 2004; 41(4):416-23. https://doi.org/10.1597/03-053.1.

38. Lo LJ, Wong FH, Chen YR, Lin WY, Wen-Ching Ko E, Kirschner RE. Palatal surface area measurement: comparisons among different cleft types. Ann Plast Surg. 2003;50(1):18-23 discussion 23-4.

39. Huang CS, Wang WI, Jein-Wein Liou E, Chen YR, Kao-Ting Chen P, Noordhoff MS. Effects of cheiloplasty on maxillary dental arch development in infants with unilateral complete cleft lip and palate. Cleft Palate Craniofac J. 2002;39(5):513-6. https://doi.org/10.1597/15451569_2002_039_0513_ eocomd_2.0.co_2.

\section{Publisher's Note}

Springer Nature remains neutral with regard to jurisdictional claims in published maps and institutional affiliations.

Ready to submit your research? Choose BMC and benefit from:

- fast, convenient online submission

- thorough peer review by experienced researchers in your field

- rapid publication on acceptance

- support for research data, including large and complex data types

- gold Open Access which fosters wider collaboration and increased citations

- maximum visibility for your research: over $100 \mathrm{M}$ website views per year

At $\mathrm{BMC}$, research is always in progress.

Learn more biomedcentral.com/submissions 